\title{
Monitoring of German Fertility: Estimation of Monthly and Yearly Total Fertility Rates on the Basis of Preliminary Monthly Data
}

\author{
Gabriele Doblhammer, Nadja Milewski, Frederik Peters
}

\begin{abstract}
This paper introduces a set of methods for estimating fertility indicators in the absence of recent and short-term birth statistics. For Germany, we propose a set of straightforward methods that allow for the computation of monthly and yearly total fertility rates $(m T F R)$ on the basis of preliminary monthly data, including a confidence interval. The method for estimating most current fertility rates can be applied when no information on the age structure and the number of women exposed to childbearing is available. The methods introduced in this study are useful for calculating monthly birth indicators, with minimal requirements for data quality and statistical effort. In addition, we suggest an approach for projecting the yearly TFR based on preliminary monthly information up to June.
\end{abstract}

Keywords: Demographic monitoring $\cdot$ Germany $\cdot$ monthly total fertility rate confidence interval $\cdot$ TFR

\section{Introduction}

Despite the increasing interest - from both population researchers and the public - in short-term trends and variations in fertility patterns in Germany, no up-todate birth statistics are currently available. There are two main reasons for the lack of recent and short-term demographic data. First, information on birth numbers is made available to scientists with a time lag. Second, the possibilities for estimating demographic measures based on monthly data have, up to this point, barely been explored.

The goal of this paper is to propose a new approach for rapidly estimating shortterm developments in fertility rates in Germany. The demographic monitoring of recent developments is especially interesting in contexts in which, for example, a new policy has been introduced, or a sudden social upheaval has occurred. The focus of this paper is, however, on the technical aspects of the proposed strategy for demographic monitoring. We leave out any theoretical, historical, political, and 
sociological framework that relates to fertility. Instead, we seek to provide a detailed demonstration of our technical approach. We provide methodological tools that will enable us to calculate monthly fertility rates, and to estimate up-to-date indicators of fertility behaviour based on aggregate monthly statistics.

Our claims and our research were inspired by the latest state-of-the-art approach for calculating monthly fertility rates, which was introduced in a study by Sobotka et al. (2005). Unfortunately, it is not possible to apply the methods and indicators used in the study for Austria to the German case, because the calculations require highquality data, such as parity-specific information, which is not available for Germany (or for many other countries). Therefore, we propose the construction of a monthly rate that serves as a basis for a relatively prompt estimation of the total fertility rate (TFR).

The paper is structured as follows. We start by describing the peculiarities and limitations of fertility data in Germany. Next, we review the literature on four approaches that have been brought up in recent years in order to solve similar data problems. After providing an overview of the different data sources in Germany that contain information on birth numbers (section 3), we introduce our method for calculating a monthly TFR, along with the confidence intervals in section 4 . The forth section deals also with the estimation of the yearly TFR on the basis of monthly data, as well as the projection of the yearly TFR after data for the first six months have become available. The fifth section presents an evaluation of our method. We conclude with a discussion and some reflections.

\section{Background}

\subsection{Motivation}

For the analysis of seasonal patterns of births (e.g., Lam/Miron 1991; Dob/hammer et al. 2000), as well as for studies in the growing field of life-course research, data that is monthly, rather than yearly, is required. The effects on fertility of an economic crisis, welfare state reforms, or legislative changes can only be observed and studied properly when recent and detailed information is available. Information on fertility behaviour that is solid and internationally comparable is, however, published with a time lag in a yearly cycle.

In Germany, the total fertility rate (TFR) for a given year is generally calculated und published in late summer of the following year. More detailed demographic data, such as the age of the women at childbirth and regional distributions, are not made available until even later dates. A further limitation of the German birth statistics is the lack of information on intra-year dynamics. For scientific or public use, no monthly data on the number of births per age of the mothers are published, mainly due to privacy restrictions. As a consequence, researchers with an interest in short-term variations in birth numbers are faced with a lack of recent and disaggregated data. 
As is the case for most other countries that maintain national statistics, the monthly summarized total number of births is the only short-term indicator that is currently available for Germany (Sobotka et al. 2005). This raw number of births is published by the Federal Statistical Office with a time lag of about three months. Both members of the media and policy makers tend to cite this raw number extensively. However, like any other crude number in demographic research, this figure has several serious shortcomings that are mostly neglected by the public: because no standardization is done, interpretations and comparisons over time and by country are very limited. Without information on the number of potential mothers exposed to childbearing, and the age structure of women who gave birth during a particular month, the number of births is almost useless for research purposes. Short-term trends and changes in births behaviour - i.e., intra-year dynamics - cannot be detected on the basis of the birth numbers currently available.

We seek to address these problems by providing a standardized monthly rate that can be continuously updated, and that is made available with little or no delay to researchers, as well as to the public. We call it the "Monitor of births". One of the key challenges in creating this monitor is to find a balance between demographic precision, which calls for a complex set of methods, and a high degree of accessibility. In addition, we strive to take into account the specific German context, observing fertility differentials between the eastern and the western federal states by calculating separate rates for the two regions.

The challenge that we have been facing in doing so is two-fold: first, we need to obtain adequate data; and, second, we need to solve the methodical problem of calculating a rate standardized for the unknown age of the mothers at childbearing, and for the unknown population at risk in a given month.

\subsection{Previous research}

\section{Monthly fertility rates}

Before describing our approach, we will review previous projects that have made similar attempts to estimate short-term trends in fertility rates. For several decades of the previous century, fertility rates were calculated exclusively on the basis of yearly data, even though monthly birth numbers were also published (Calot/Nadot 1977). These two demographic sources were linked for the first time in 1977 in France by Calot and Nadot (1977). Although they used monthly birth data, their stated goal was the estimation of the expected number of births for the current year.

The first method for the observation of monthly fertility rates was introduced four years later (Calot 1981) ${ }^{1}$. In contrast to the ideas Calot and Nadot developed in 1977 , the new method used only one data source on monthly births, and was simul-

1 This paper, later termed "the Calot method", was translated and published in German in the same year by Höhn (1981). 
taneously applied to France, Germany, and England and Wales (Calot 1981). Due to the lack of age-specific information on births and the number of women exposed to childbearing, Calot made a detailed investigation of the relationship between the yearly total number of births and the total fertility rate. He separated the two measures in order to calculate the mean size of the female population of reproductive ages. To calculate an estimated monthly TFR of the most recent year, the TFR and the population numbers from the most recent year of observation were used, adjusted for seasonal variations and the different lengths of months and the distribution of weekdays per month (Calot 1981). To evaluate the accuracy of his method, Calot analyzed separately any possible errors due to changes in the female population and age-specific fertility rates. The analysis showed that the deviation per calendar year from 1971 to 1983 was no more than two percent. These errors were mainly attributed to migration and changes in the mean age at birth (Calot 1981).

This method can be referred to as the "historic approach", because it is not applied today, even though comprehensive plans to establish an international monitoring system of monthly fertility rates did exist ${ }^{2}$ (Höhn 1981). We can only speculate as to why Calot's method failed to become widely accepted: First, the fundamental basis of the method - i.e., the relationship between the summary measures TFR and total number of births, expressed as a mean generational size - may have been too unconventional to find a place in the practices of the federal statistical calculation system. Second, Calot calculated the error of his estimated mean generational size, but failed to evaluate the preliminary birth counts against the later published final numbers. A further problem is related to the inclusion of weekday coefficients to control for the different numbers of weekdays and weekend days in each month. ${ }^{3}$ Even though a bias is caused by such heterogeneity, in many countries the necessary information on daily records is not available, and the avoided error is so small that providing an additional data source and calculation method would be far out of proportion to the benefits of doing so.

Today, there are two approaches that are being used to calculate and publish monthly fertility rates, which we refer to here as "recent approaches". The first method was developed and applied by the Office for National Statistics in England and Wales (ONS 2009), with the goal of calculating monthly fertility rates for past years, but not for the present year. Accordingly, no estimation of births or use of preliminary data is performed, but a correction for seasonal fluctuations is made. Seasonal fluctuations are eliminated through the application of the X-11 algorithm method. The denominator for each monthly rate is calculated by linear interpolation between two known mid-year populations (ONS 2009).

2 In addition to England and Wales, France, Germany, Hungary, the Netherlands, Switzerland, Spain, and Portugal planned to implement the "Calot method" (Höhn 1981).

3 On Sunday and Saturday the number of births is up to $20 \%$ lower than during the week (Höhn 1981). 
The second, more recently developed approach is the "Fertility Monitoring System" of the Vienna Institute of Demography (VID). This approach, which is the only method for calculating monthly TFR on the basis of preliminary and the most recent data, has been described by Sobotka et al. (2005); here termed as "Sobotka approach". These authors have developed an innovative and complex method that differs fundamentally from its predecessors. They calculate total fertility rates for each birth order separately. In combination with an exposure-specific female population denominator, a period average parity (PAP), based on parity progression ratios, is then calculated. Hence, in addition to being standardized for age and parity, the resulting number is not affected by tempo effects. The similarity of this method to previous approaches lies in the adaptation of seasonal and calendar factors. Furthermore, they have resolved the problem of instable endings in smoothed time series through the use of auto-regressive, integrated moving-average models (ARIMA), in combination with the Box-Jenkins method (Sobotka 2005).

While Sobotka et al. have succeeded in creating a high-quality system of fertility monitoring for Austria, demographers who want to use the Sobotka approach to create a birth monitoring system in other countries face a serious problem: for this approach to work, disaggregated individual data is needed. Complete data on birth order, the date of the previous birth, and the yearly age- and order-specific distribution of women exposed to a birth of a certain order, as well as on daily births, are very rarely available. Thus, the application of the Austrian method to other countries is seldom possible, and Calot's (1981) original idea of constructing an indicator which allows international comparisons is, even today, not fully realized.

To sum up, we can report that historic and recent approaches have been developed to observe and estimate monthly reproductive behaviour. Of the approaches that use preliminary data, only the method developed by Sobotka et al. is in use today. Most attempts have failed to provide an easy-to-understand and easy-to-calculate indicator. Based on the lessons of the failure of the Calot method, these two fundamental characteristics should be demanded from an indicator, which could persist for more than just a couple of years.

\section{Yearly fertility rates}

Up to the present, no method for estimating a yearly TFR based on preliminary monthly data has been developed. So far, there have only been attempts at calculating the yearly number of births, as mentioned above (Calot/Nadot 1977).

Calot and Nadot proposed a procedure for estimating in advance the number of births that will be observed throughout the current year. In order to make this kind of short-term forecast, two data sources on monthly births are used. The first source contains a provisional number of births, based on manual counts of birth certificates, and published with a delay of at least three months. The second data source is even more up-to-date: it consists of a selected number of births in certain French towns that were released one month after they occurred. In order to estimate the total number of yearly births, a linear extrapolation technique based on the ratio of both sources and a seasonal variation factor was applied (Calot/Nadot 1977). 
According to the evaluations of the authors themselves, the mean quadratic error of this extrapolation depends on the distance of the month to the forecast and the amount of provisional data available in the respective year. Because this error is normally distributed, a $95 \%$ confidence interval could be computed (Calot/Nadot 1977).

Even though their approach seemed to work quite well, the authors did not implement it in a regular report. In addition, no effort to calculate a rate instead of the number of births was made.

\section{$3 \quad$ Data}

For Germany, four different types of birth data exist (see Tab. 1); three of them contain information about the month of birth. These datasets differ in terms of regional classification, time reference, and time lag of release; and each set of data has its specific limitations. First, the most recent source, labeled N1 (we use the names of the datasets as given by the statistical offices), contains the number of births provided by the Federal Statistical Office about three months after the submission of the number of births from the local offices of vital statistics (Standesämter) to the statistical offices of the federal states (Länder). It is important to note that the date of this information does not necessarily match the date of birth. Most significantly, births that occur at the end of December often are not registered by the office of vital statistics until January of the following year.

Second, after the births were reported by the offices of vital statistics to the statistical office of the federal states, these Länder offices add the place of residence of the parents to the statistics and check the data for plausibility. The result of this procedure is aggregated in the preliminary statistics $N 10$, which also contains the variable "Federal state". While it contains a considerable amount of information, a major problem with this dataset is that all implausible cases are initially excluded, and are not entered into the statistics until a much later date, following clarification of each case. Thus, notable numbers of births are systematically missing every month. It is important to note that the cases that are excluded from N10 because of implausibility are not added to $N 10$ at any time in the future, but are, rather, included in the final dataset $N 30$.

Third, the $N 30$ statistics by the Federal Statistical Office provides aggregated birth numbers upon request, and also contains information on the ages of the mothers in one-year age groups, as well as on the mothers' places of residence, and on the revised implausible cases. These numbers are not published until another year has passed, and, unfortunately, they appear without any information on a monthly or regional basis. In order to distinguish this source from the fourth dataset, we call it $N 30 a$, where "a" indicates aggregated data.

Fourth, the disaggregated data from $N 30$ become available with a time lag of about one year at the Federal Research Data Center (Forschungsdatenzentrum at the Federal Statistical Office or the Statistical Offices of the Federal States), but this data can only be accessed by making an official request. We call this scientific-use 
Tab. 1: Types of monthly birth data in Germany

\begin{tabular}{|c|c|c|c|c|c|c|}
\hline Data source & $\begin{array}{l}\text { Type of } \\
\text { data }\end{array}$ & $\begin{array}{l}\text { Regional } \\
\text { depth }\end{array}$ & $\begin{array}{l}\text { Age of the } \\
\text { mother at } \\
\text { birth }\end{array}$ & $\begin{array}{l}\text { Time } \\
\text { reference }\end{array}$ & $\begin{array}{l}\text { Time lag of } \\
\text { release by } \\
\text { Federal } \\
\text { Statistical } \\
\text { Office }\end{array}$ & $\begin{array}{l}\text { Other } \\
\text { characteristics }\end{array}$ \\
\hline$N 1$ & $\begin{array}{l}\text { Aggregated } \\
\text { number of } \\
\text { births }\end{array}$ & $\begin{array}{l}\text { Total } \\
\text { Germany }\end{array}$ & No & Month & $>3$ months & $\begin{array}{l}\text { Date of } \\
\text { registration at the } \\
\text { Office of Vital } \\
\text { Statistics }\end{array}$ \\
\hline N10 & $\begin{array}{l}\text { Aggregated } \\
\text { number of } \\
\text { births }\end{array}$ & $\begin{array}{l}\text { Federal } \\
\text { State }\end{array}$ & No & Month & $>6$ months & $\begin{array}{l}\text { Place of } \\
\text { residence, date of } \\
\text { birth, excluding } \\
\text { implausible cases }\end{array}$ \\
\hline N30a & $\begin{array}{l}\text { Aggregated } \\
\text { number of } \\
\text { births }\end{array}$ & District & Yes & Year & $>9$ months & $\begin{array}{l}\text { Place of } \\
\text { residence, date of } \\
\text { birth including } \\
\text { implausible cases }\end{array}$ \\
\hline N30suf & $\begin{array}{l}\text { Individual } \\
\text { level }\end{array}$ & District & Yes & Month & $>12$ months & $\begin{array}{l}\text { Place of } \\
\text { residence, date of } \\
\text { birth, including } \\
\text { implausible cases }\end{array}$ \\
\hline
\end{tabular}

Source: Statistical Offices in Germany

file N30suf. These data contain monthly information, together with the age of the mother, as well as a regional breakdown to the district level for all individual cases. Figure 1 shows the deviations of each preliminary data source (N1 and N10) from the final official result $N 30$ suf for the total number of children born in 2007. The lower degree of accuracy of the later published statistics N10 is an unexpected finding. While $N 1$ differs no more than $10 \%$ from $N 30$ suf within a given month, over the long term, N10 varies about -/ $+25 \%$, especially in January and December. The cause of this paradoxical phenomenon is a cumulative effect of the inclusion of those cases that were initially considered implausible, and were only later included in N30suf.

Because of this shortcoming, we decided to use the less accurate source N10 for the comparison between eastern and western Germany only. For the calculation of the rate for all of Germany, the data quality of $N 1$ is superior until N30suf is finally published. Due to the systematic under- and over-coverage of the preliminary monthly birth statistics, a weighting factor for January and December must be added, at least for the data contained in N10.

Since the time lag of the publication of the official statistics is also important, Table 2 shows the dates and types of the announcements of the Federal Statistical Office in the year 2009. The official German TFR for 2009 was published in September 2009. At this time, the number of births in N10 and N1 for 2009 was updated for March (N10) and June (N1), as well. The final result N30 for 2008 did not become available at the Federal Research Data Center until December 2009; by this time, the preliminary data had already been updated to July 2009 and September 2009. 
Fig. 1: Deviation between the absolute monthly number of births in the $N 1$ and N10 statistics and the official result N30suf, Germany, 2007 (\%)

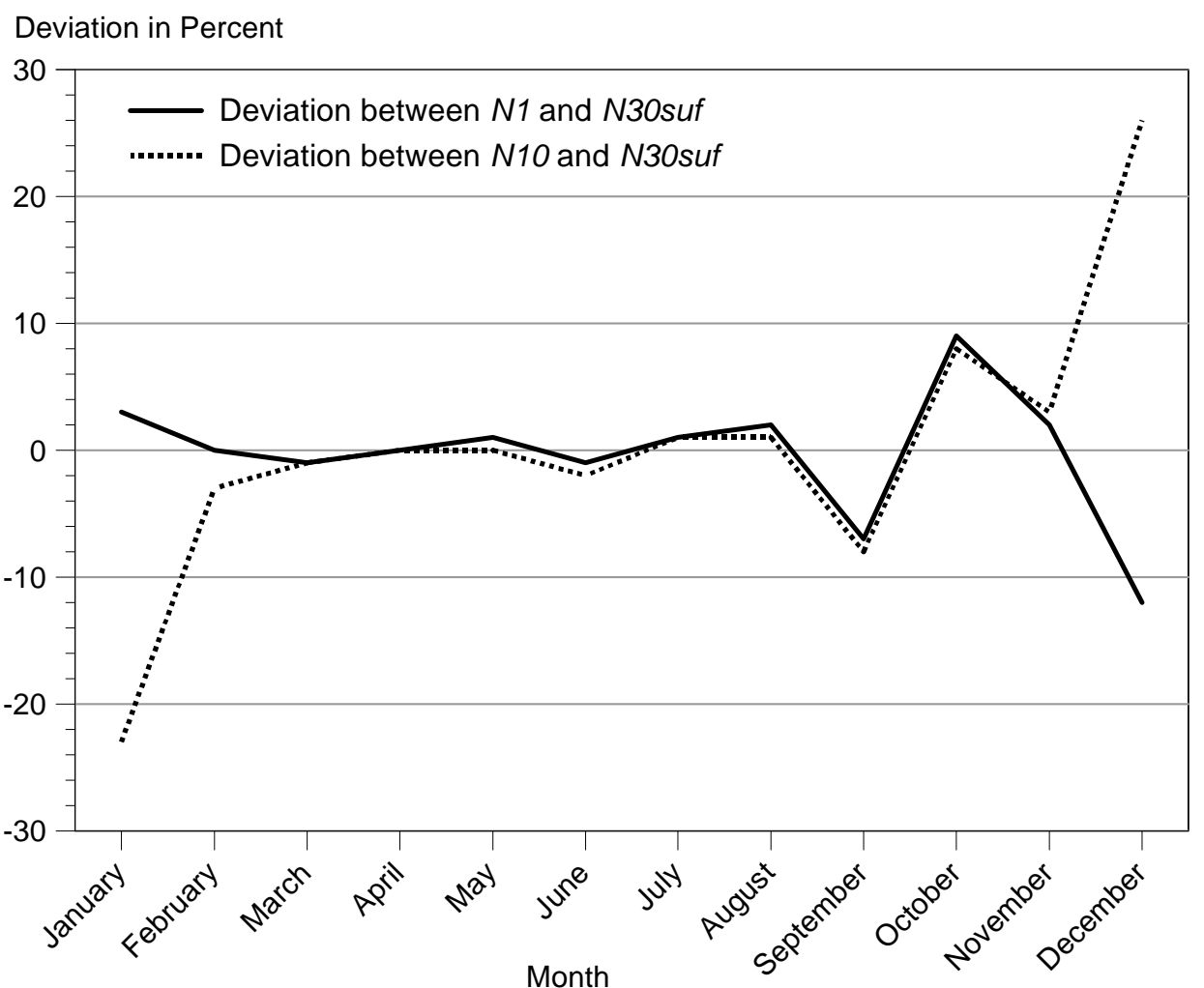

Source: Federal Statistical Office Germany

In addition to information about births, data on the population at risk is needed in order to calculate demographic rates. We approximate the female population at risk by the mid-year population $\bar{P}_{[15,45]}^{f}$ to be in the age range 15 to 45 . Since accurate data for women that are monthly and age-specific are not available, we use the official annual figures on the numbers of people residing in Germany, which implies the assumption of equally distributed censoring events (death and migration) during a calendar year.

Like the yearly TFR, the mid-year population numbers are published by the Federal Statistical Office with a lag of at least 10 months after the end of a given calendar year. A simple up-to-date estimation for calendar year $t$ could be obtained by using the population at risk from the previous year:

$$
\bar{P}_{[15,45]}^{f}(t)=\bar{P}_{[14,44]}^{f}(t-1)
$$


Tab. 2: Dates of announcements by the Federal Statistical Office regarding birth data (years 2008 and 2009)

\begin{tabular}{ll}
\hline Month & Type of Announcement \\
\hline September 2009 & Official TFR for Germany in 2008 (N30a) \\
September 2009 & Number of births by Federal Länder in March 2009 (N10) \\
September 2009 & Number of births in June 2009 (N1) \\
December 2009 & $\begin{array}{l}\text { Final result for the year 2008 (N30suf) becomes available at } \\
\text { the Federal Research Data Center }\end{array}$ \\
December 2009 & Number of births by Federal Länder in July 2009 (N10) \\
December 2009 & Number of births for Germany in September 2009 (N1) \\
\hline
\end{tabular}

Source: Federal Statistical Office Germany

Accordingly, a small bias may be caused by migration and the number of deaths that occur during the preceding year. As will be seen later in our results section, this does not constitute a major problem for Germany as a whole, but introduces a bias for East Germany.

\section{$4 \quad$ Methods}

We develop one approach for calculating monthly fertility rates on the basis of the preliminary data $N 1$ and $N 10$, and label them "preliminary $m T F R^{\prime \prime}$. Then we estimate a preliminary yearly TFR that is based on N1, and which is available well before the official announcement. We also calculate the final TFR on a monthly and a yearly basis once all the final data of a year have become available, and label this the "final mTFR (monthly)" and the "final TFR (yearly)".

We test the significance of the difference in the final mTFRs of the current and previous years by assuming that the number of births follows a Poisson distribution.

Finally, we project the yearly total fertility rate as soon as the preliminary data have become available for the first half of the current year (January to June); this figure is labelled the "projected yearly TFR".

\subsection{Estimating monthly total fertility rates}

\section{Estimation of the final mTFR}

The final mTFR can be computed accurately on the basis of the final data N30suf. Since the births included in this data, here referred as $B_{x}^{\text {N30suf }}$, are classified by months and the age $x$ of the mother, and the population at risk is known (as derived 
from equation 1), a final $\operatorname{mTFR}(m, t)$ for month $m$ and calendar year $t$ can be obtained by (2):

$$
m T F R(m, t)=\sum_{x=15}^{x=45} \frac{B_{x}^{N 30 \text { suf }}(m, t)}{\bar{P}_{x}^{f}(t)} \cdot \operatorname{caf}(m, t)
$$

Note that we introduce here the calendar adjustment factor caf $(m, t)$, which standardizes each month $m$ to $1 / 12$ of each calendar year $t$. The factor caf $(m, t)$ is calculated by dividing the number of days of a particular month $n(m)$ by the number of days of the given year $n(t)$. The term is then multiplied by 12 in order to construct an easy-to-interpret indicator as follows:

$$
\operatorname{caf}(m, t)=\frac{n(t) / 12}{n(m)} \cdot 12=\frac{n(t)}{n(m)}
$$

As a result, the $\operatorname{mTFR}(m, t)$ for month $m$ and calendar year $t$ expresses the average number of children a woman would have if the conditions of the particular month $m$ were constant throughout the whole year $t$.

\section{Estimation of the preliminary mTFR}

For computing most recent fertility rates, based on the statistics $N 1$ and $N 10$ (which are available well before $\mathrm{N} 30$ suf), an additional intermediary step is necessary, since only the total number of births, without any information on the age of the mothers at birth, are available here.

We assume that the age-specific birth rates of a given year $r_{x}(t)$ are the same as in the preceding year. ${ }^{4}$

$$
r_{x}(t)=\frac{B_{x}^{N 30 \text { suf }}(t-1)}{\bar{P}_{x}^{f}(t-1)}
$$

Subsequently, the monthly number of births per age can be obtained by multiplying the number of women of the previous year $\bar{P}_{[x-1]}^{f}(t-1)$ by the recent birth rate $r_{x}(t)$.

$$
B_{x}^{\text {const }}(t)=r_{x}(t) \cdot \bar{P}_{[x-1]}^{f}(t-1)
$$

4 Originally, we had in this case used the approach that the expected relative number of births per age and month is the same as the relative number of births per age in the preceding year. In the evaluation of our results, we compared both approaches and found that they produced almost equal results; deviations occurred only on the third decimal (Peters/Milewski/Dob/hammer 2009). 
The resulting number $B_{x}^{\text {const }}(t)$ represents the births per age that would have been observed if the age-specific fertility rates had been identical to year $(t-1)$. Accordingly, we can now answer the following question: "How many births would have been observed in the respective age if the TFR had been the same as in the previous year, and no changes in the age distribution had occurred?"

In order to calculate the number of births per age which fit to the observed total number in the statistics $N 1$ or N10, a weighting procedure has to be adopted:

$$
B_{x}^{N 1}(m, t)=\frac{B_{x}^{\text {const }}(t)}{\sum_{x=15}^{x=45} B_{x}^{\text {const }}(t)} \cdot B^{N 1}(m, t)
$$

For computing the age-specific births for eastern and western Germany, $B^{N 10}(m, t)$, instead of $B^{N 1}(m, t)$, is used in equation 6 .

According to equation 2, the preliminary monthly total fertility rate for Germany, labelled $m T F R$, is calculated by summing up the age-specific birth rates over ages 15 to 45 :

$$
\operatorname{mTFR}(m, t)=\sum_{x=15}^{x=45} \frac{B_{x}^{N 1}(m, t)}{\bar{P}_{[x-1]}^{f}(t-1)} \cdot \operatorname{caf}(m, t)
$$

In the same manner, the total fertility rates for eastern and western Germany are computed as:

$$
\operatorname{mTFR}(m, t)=\sum_{x=15}^{x=45} \frac{B_{x}^{N 10}(m, t)}{\bar{P}_{[x-1]}^{f}(t-1)} \cdot \operatorname{caf}(m, t)
$$

Since the number of births in N10 for western Germany is systematically underestimated in January by about $25 \%$ (20\% for eastern Germany), and is systematically overestimated in December by approximately $25 \%$ (20\% for eastern Germany) (see Fig. 1), a weighting factor for these months is specified. This factor is termed error $e$, and is 0.25 for western Germany and 0.2 for eastern Germany.

$$
\begin{aligned}
& \operatorname{caf}_{\text {January }}(t)=\frac{n(t) \cdot(1+e)}{n(m)} \\
& \operatorname{caf}_{\text {December }}(t)=\frac{n(t) \cdot(1-e)}{n(m)}
\end{aligned}
$$




\section{Estimation of the preliminary yearly TFR}

In addition to allowing us to observe monthly fertility behaviour, our approach for monitoring births in Germany meets the demand for an up-to-date yearly TFR. Normally, this indicator is officially published by the Federal Statistical Office for the previous year around August ${ }^{5}$ of the following year, while the preliminary number of total births in a calendar year $N 1$ is already available in early spring of the following year.

Due to this time lag, we decided to estimate a yearly TFR that is based on N1, and which can be made available before the official announcement. Again, the major problem that we had to solve was the missing information on the age structure of the mothers. As for monthly fertility, only the total number of births is available for the previous year, and the population at risk is unknown.

As was done for the computation of the monthly TFR, we assume that neither mortality nor migration occurred among the women in reproductive ages during the previous year. The population at risk can then be computed according to equation (1).

In order to obtain age-specific fertility rates without having any information on the age-at-birth distribution, we use the respective distribution of the previous year. As was done in estimating preliminary monthly age-specific births counts, $r_{x}(t)$ of equation 4 is used for estimating yearly data, performed in equation 10.

$$
B_{x}^{\text {const }}(t)=r_{x}(t) \cdot \bar{P}_{[x-1]}^{f}(t-1)
$$

As $B_{x}^{\text {const }}(t)$ represents the number of births that would be expected if fertility rates had been the same as in the preceding year; equation 11 weights this number by the actually observed preliminary number of births.

$$
B_{x}^{N 1}(t)=\frac{B_{x}^{\text {const }}(t)}{\sum_{x=15}^{x=45} B_{x}^{\text {const }}(t)} \cdot B^{N 1}(t)
$$

Finally, the preliminary yearly TFR for Germany can be computed analogically to our monthly procedure:

$$
\operatorname{TFR}^{N 1}(t)=\sum_{x=15}^{x=45} \frac{B_{x}^{N 1}(t)}{\bar{P}_{[x-1]}^{f}(t-1)}
$$

5 The official TFR for 2007 was published on August 20, 2008; www.destatis.de/jetspeed/portal/ $\mathrm{cms} /$ Sites/destatis/Internet/DE/Presse/pm/2008/08/PD08_298_12641, templateld=renderPri nt.psml [Access: 07/14/2009]. The official TFR for 2008 was published on September 3rd 2009: www.destatis.de/jetspeed/portal/cms/Sites/destatis/Internet/DE/Presse/pm/2009/09/PD09 327__12641,templateld=renderPrint.psml 
The quality of this preliminary yearly TFR depends, first, on the degree of mismatch between the preliminary and the final total number of births; and, second, on the amount of variation in age-specific distributions of births. Generally, these limitations should not seriously distort the estimated TFR, because the preliminary number of births $N 1$ usually has few missing cases, and fertility behaviour concerning age may not change dramatically from one year to another.

\section{Significance test of the difference in the TFR of the current month compared to the same month of the previous year}

One of the most characteristic features of monthly fertility rate measurement is its seasonal pattern (c.f. Flaskämper 1962: 258f.; Doblhammer et al. 2000) ${ }^{6}$. Therefore, significant trends in fertility cannot be detected by comparing monthly TFRs during one year. In addition, we have to control for calendar-month variation by comparing fertility rates of a particular month to the fertility rates in the same month of the previous year:

$$
\operatorname{Deviation}(m, t)=\operatorname{mTFR}(m, t)-m \operatorname{TFR}(m, t-1)
$$

Another important issue that arises when observing monthly time series involves the distinction between random and systematic variations. Due to the high degree of uncertainty of preliminary data, we will not compute any form of test statistics for monthly calculated fertility rates on the basis of $N 1$ and N1O. Thus, we will only test differences on the basis of N30suf. Note that this approach works for monthly, as well as for yearly data.

A first approximation involves treating births occurring in a certain month by a fixed number of women of a specific age as rare events, ${ }^{7}$ and therefore as the realization of a Poisson distribution. Accordingly, the estimated age-specific variance of births is:

$$
\operatorname{Var}\left(A S B R_{x}^{N 30 \text { suf }}\right)=\frac{B_{x}^{N 30 \text { suf }}}{\left(\bar{P}_{[x-1]}^{f}\right)^{2}}
$$

By treating births at each age as stochastically independent from one another, the variance for the TFR can be computed by summing up the age-specific variances from ages 15 to $45:^{8}$

6 We decided to avoid eliminating seasonal fluctuations by a certain algorithm since the preliminary data used as input do not include stable seasonal patterns.

7 Rare events are characterized by the probability of occurrence converging to zero, while, at the same time, the number of trials converges to infinity.

8 The sum of Poisson-distributed random variables follows a Poisson distribution whose parameter is the sum of the component parameters. 


$$
\operatorname{Var}\left(T F R^{N 30 s u f}\right)=\sum_{x=15}^{x=45} \frac{B_{x}^{N 30 s u f}}{\left(\bar{P}_{[x-1]}^{f}\right)^{2}}
$$

Given a sufficiently large number of births we can approximate the Poisson distribution by the Normal distribution and we compute the confidence interval of the TFR by the following formula:

$$
\text { LowerLimit / UpperLimit }=T F R^{N 30 \text { suf }} \pm z_{0.83} \cdot \sqrt{\operatorname{Var}\left(T F R^{N 30 \text { suf }}\right)}
$$

We follow Payton et al. (2003), who demonstrate that non-overlapping confidence intervals corresponding to an $\alpha$-error of $17 \%\left(z_{0.83}=1.0\right)$ are sufficient to approximate a significance test based on an $\alpha$-error of 0.05 (Payton et al. 2003: 5).

\section{Projection of the yearly TFR based on the first six months of the current year}

In addition to the estimation of a preliminary yearly TFR, our goal is the projection of the final yearly TFR on the basis of the births that occurred in the first half of the current year. For example, to estimate a TFR in 2007, we calculated the proportion of the cumulated preliminary mTFR up to June from the later observed final TFR ${ }^{\mathrm{N} 30 \mathrm{a}}$, as published by the Federal Statistical Office, separately for the period 2001-2006, according to equation 17.

$$
p(t)=\frac{\sum_{m=J a n}^{m=J u n} m T F R^{N 1}(m, t)}{T F R^{N 30 a}}
$$

The geometric mean $\bar{p}$ of these six proportions is almost exactly $50 \%$, as seen in Table 5, and serves as a weighting factor for the projection of the yearly TFR, demonstrated in equation 18.

$$
T F R^{\prime}(t)=\bar{p}(t-1 \quad, \ldots, \quad t-6) \cdot \sum_{m=J a n}^{m=J u n} m T F R^{N 1}(m, t)
$$

\section{Evaluation of the estimates of the preliminary monthly and yearly TFRs}

For the evaluation of our approach, we use the year 2007 (additional material for the years 2001 to 2006 is displayed in the Appendix). We start by evaluating the estimates of the monthly TFRs for Germany (Tab. 3A). Then we review our preliminary monthly estimates for eastern and western Germany (Tab. 3B-C). Finally, we 
evaluate our estimates of the preliminary yearly TFR (Tab. 4A-C) and show our early projection of the TFR of the current year on the basis of six-month data (Tab. 5).

\subsection{Monthly fertility rates}

\section{Germany}

Table 3A presents the results for the preliminary and the final $m T F R$. The second column, final $m T F R$, contains the final rate for the respective month, together with the confidence intervals (in columns 3 and 4, UL: Upper Limit, LL: Lower Limit), as calculated on the basis of N30suf. Column 5 contains our preliminary $m T F R$, calculated on the basis of N1. Column 6 shows the absolute deviation of our estimate from the final $m T F R$.

The calculations for total Germany are based on the earliest available statistics (N1). When using N1, the biggest absolute deviation appears in December (-0.15), with comparatively large deviations also seen in September and October 2007. The deviations are somewhat smaller in the preceding years (see Tab. A1a in the Appendix), and appear more frequently in January and April. Figure 2A displays the average percentage deviation and the span of the percentage deviations for the years 2001 to 2007.

\section{Western Germany and eastern Germany}

Table 3B shows the values of the mTFR for western Germany, while Table $3 \mathrm{C}$ displays the corresponding values for eastern Germany.

The calculations for western and eastern Germany are based on a different data source (i.e., N10) than the estimations for Germany (N1). It should be noted that, whereas Berlin is included in the German $m T F R$, it is excluded from the western and eastern TTFR; here we follow the common practice of the statistical offices. In addition, N10 excludes implausible cases. Therefore, the German estimates cannot be compared to the eastern-western results. (Example: We calculate a preliminary German $m$ TFR of 1.39 for January 2007, but the rate for western Germany is 1.31, and the rate for eastern Germany 1.26. This indicates that a proportion of the births are missing in the regional $m T F R$.)

Nevertheless, the deviation of our preliminary western German mTFR from the final result based on N30suf (Tab. 3B, Tab. A1b in the Appendix) is, on average, small. The maximum absolute deviation in 2007 is 0.13 in October. Figure 2B shows the average percentage deviation and the span of percentage deviations for western Germany in the years 2001 to 2007. Whereas our estimates for western Germany show positive and negative deviations from the final $m T F R$, the trend is different for eastern Germany (Tab. $3 \mathrm{C}$ and $\mathrm{A} 1 \mathrm{C}$ in the Appendix): Here, we underestimate the preliminary $m T F R$ by about roughly three percent, or, in absolute values, between -0.15 to -0.12 . We assume that this systematic underestimation is related to our assumptions that there is no out-migration from eastern Germany, and that we can use the population structure of the previous year as an approximation of the current 
Tab. 3: Estimations of $m T F R$ in 2007 - confidence intervals and absolute errors

\begin{tabular}{lccccc}
\hline & \multicolumn{5}{c}{ A) Germany } \\
Month & $\begin{array}{c}\text { Final } m \text { TFR } \\
\text { (N30suf) }\end{array}$ & Confidence intervall & UL & LL & Preliminary $m$ TFR \\
(N1) & $\begin{array}{c}\text { Deviation preliminary } m \text { TFR } \\
\text { from final } m \text { TFR }\end{array}$ \\
\hline January & 1.35 & 1.35 & 1.34 & 1.39 & 0.04 \\
February & 1.33 & 1.34 & 1.32 & 1.34 & 0.01 \\
March & 1.32 & 1.33 & 1.31 & 1.31 & -0.01 \\
April & 1.25 & 1.25 & 1.24 & 1.25 & 0.00 \\
May & 1.33 & 1.33 & 1.32 & 1.34 & 0.01 \\
June & 1.40 & 1.41 & 1.39 & 1.39 & -0.01 \\
July & 1.46 & 1.46 & 1.45 & 1.48 & 0.02 \\
August & 1.47 & 1.48 & 1.46 & 1.51 & 0.03 \\
September & 1.51 & 1.52 & 1.50 & 1.40 & -0.11 \\
October & 1.40 & 1.41 & 1.39 & 1.53 & 0.13 \\
November & 1.32 & 1.33 & 1.31 & 1.36 & 0.04 \\
December & 1.29 & 1.30 & 1.29 & 1.14 & -0.15 \\
\hline
\end{tabular}

Source: Calculations based on $N 1$ and $N 30$ suf.

B) Western Germany

\begin{tabular}{|c|c|c|c|c|c|}
\hline \multirow[b]{2}{*}{ Month } & \multirow{2}{*}{$\begin{array}{l}\text { Final } m T F R \\
\text { (N30suf) }\end{array}$} & \multicolumn{2}{|c|}{ Confidence intervall } & \multirow{2}{*}{$\begin{array}{l}\text { Preliminary mTFR } \\
\text { (N10) }\end{array}$} & \multirow{2}{*}{$\begin{array}{l}\text { Deviation preliminary } m T F R \\
\quad \text { from final } m T F R\end{array}$} \\
\hline & & UL & $\mathrm{LL}$ & & \\
\hline January & 1.37 & 1.38 & 1.36 & 1.31 & -0.06 \\
\hline February & 1.34 & 1.35 & 1.33 & 1.32 & -0.02 \\
\hline March & 1.33 & 1.34 & 1.32 & 1.32 & -0.01 \\
\hline April & 1.25 & 1.26 & 1.24 & 1.26 & 0.01 \\
\hline May & 1.33 & 1.34 & 1.32 & 1.34 & 0.01 \\
\hline June & 1.40 & 1.41 & 1.39 & 1.38 & -0.02 \\
\hline July & 1.45 & 1.46 & 1.44 & 1.46 & 0.01 \\
\hline August & 1.48 & 1.49 & 1.47 & 1.50 & 0.03 \\
\hline September & 1.50 & 1.51 & 1.49 & 1.40 & -0.11 \\
\hline October & 1.40 & 1.41 & 1.39 & 1.53 & 0.13 \\
\hline November & 1.33 & 1.34 & 1.32 & 1.37 & 0.04 \\
\hline December & 1.30 & 1.31 & 1.29 & 1.24 & -0.06 \\
\hline
\end{tabular}

Note: January weighted by 0.75 , December weighted by 1.25 .

Source: Calculations based on N10 and N30suf.

\begin{tabular}{|c|c|c|c|c|c|}
\hline \multicolumn{6}{|c|}{ C) Eastern Germany } \\
\hline \multirow[b]{2}{*}{ Month } & \multirow{2}{*}{$\begin{array}{l}\text { Final } m \text { TFR } \\
\text { (N30suf) }\end{array}$} & \multicolumn{2}{|c|}{ Confidence intervall } & \multirow{2}{*}{$\begin{array}{l}\text { Preliminary } m T F R \\
\text { (N10) }\end{array}$} & \multirow{2}{*}{$\begin{array}{c}\text { Deviation preliminary } m T F R \\
\text { from final } m T F R\end{array}$} \\
\hline & & UL & $\mathrm{LL}$ & & \\
\hline January & 1.31 & 1.33 & 1.29 & 1.26 & -0.05 \\
\hline February & 1.30 & 1.32 & 1.28 & 1.25 & -0.04 \\
\hline March & 1.30 & 1.32 & 1.28 & 1.27 & -0.03 \\
\hline April & 1.24 & 1.26 & 1.22 & 1.19 & -0.05 \\
\hline May & 1.34 & 1.36 & 1.32 & 1.33 & -0.01 \\
\hline June & 1.44 & 1.46 & 1.42 & 1.37 & -0.07 \\
\hline July & 1.51 & 1.53 & 1.49 & 1.51 & 0.00 \\
\hline August & 1.49 & 1.52 & 1.47 & 1.48 & -0.01 \\
\hline September & 1.55 & 1.57 & 1.53 & 1.39 & -0.15 \\
\hline October & 1.39 & 1.41 & 1.37 & 1.44 & 0.05 \\
\hline November & 1.30 & 1.32 & 1.28 & 1.35 & 0.04 \\
\hline December & 1.25 & 1.27 & 1.23 & 1.18 & -0.08 \\
\hline
\end{tabular}

Note: January weighted by 0.8, December weighted by 1.2 .

Source: Calculations based on N10 and N30suf. 
Fig. 2: Average percentage deviation (solid line) and span of deviations of the preliminary $m T F R$ from the final $m T F R$ - years 2001 to 2007

\section{A) Germany}

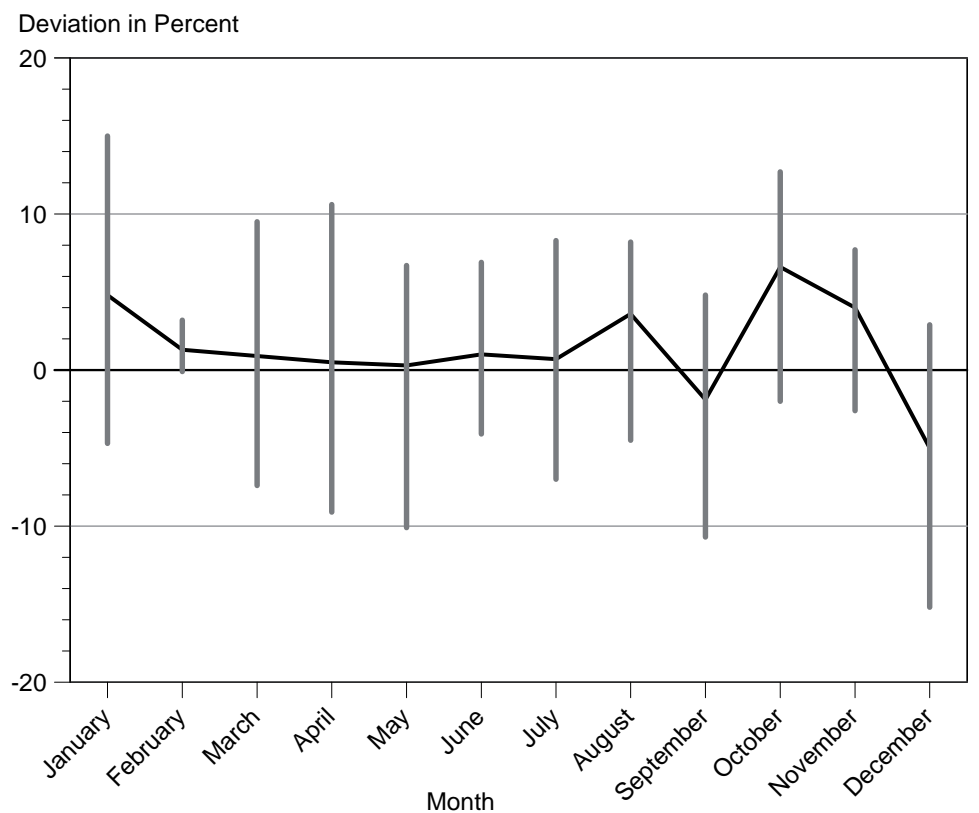

B) Western Germany

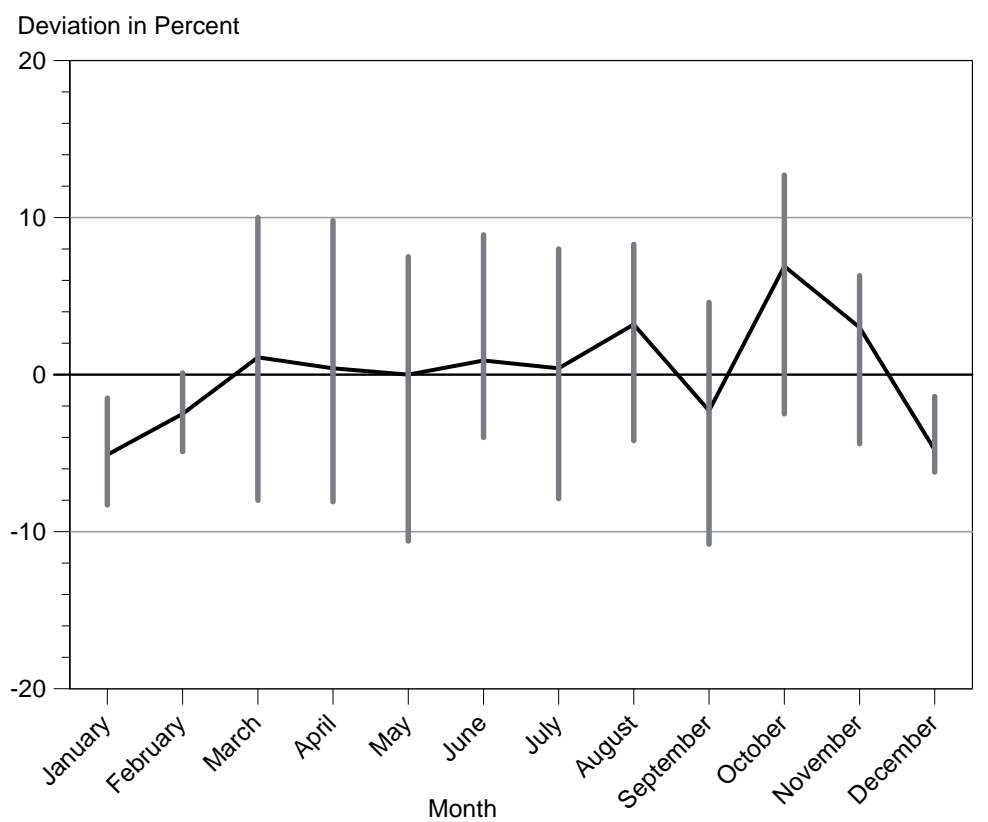




\section{C) Eastern Germany}

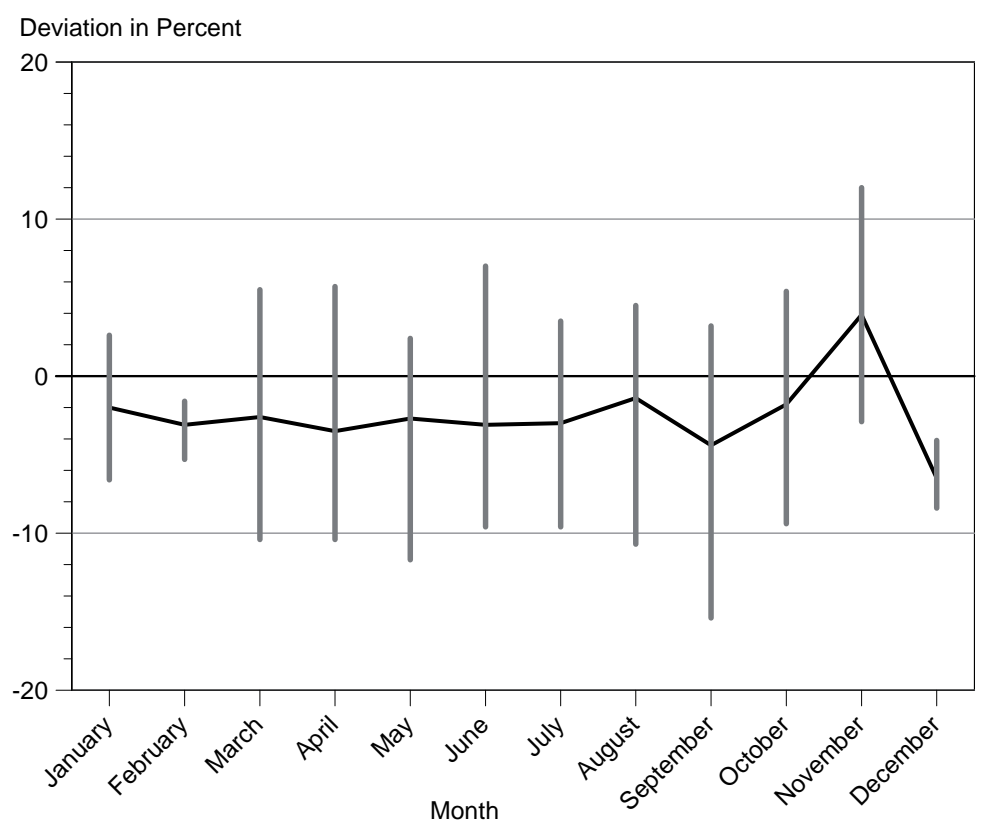

Source: Calculations based on N1,N10 and N30suf.

year's risk population. In addition, a real increase in birth numbers may have occured in the second half of the year, which would be underestimated by our mTFR.

\subsection{Yearly fertility rates}

\section{Estimation}

After the preliminary data of all months have been published, we estimate the preliminary yearly TFR. Table 4 shows the final TFR (calculated on the basis of N30suf; column 2) and its confidence intervals (columns 3 and 4), our estimation on the basis of $N 1$ and N10, respectively, and its deviation from the final TFR (columns 5 and 6).

For all of Germany (Tab. 4A), our estimates of the preliminary yearly TFR deviate from the final figures on average by $+/ 0.01$, while the maximum deviation is 0.03 . The average deviation for western Germany (Table 4B) is zero, while for eastern Germany, it is -0.03 (Tab. 4C). 
Tab. 4: Estimations of yearly TFR - confidence intervals and absolute errors for the years 2001 to 2007

\begin{tabular}{|c|c|c|c|c|c|}
\hline \multicolumn{6}{|c|}{ A) Germany } \\
\hline \multirow[b]{2}{*}{ Year } & \multirow{2}{*}{$\begin{array}{l}\text { Final TFR } \\
\text { (N30suf) }\end{array}$} & \multicolumn{2}{|c|}{ Confidence intervall } & \multirow{2}{*}{$\begin{array}{l}\text { Preliminary TFR } \\
\text { (N1) }\end{array}$} & \multirow{2}{*}{$\begin{array}{l}\text { Deviation preliminary TFR } \\
\text { from final TFR }\end{array}$} \\
\hline & & UL & LL & & \\
\hline 2001 & 1.35 & 1.35 & 1.34 & 1.35 & 0.00 \\
\hline 2002 & 1.34 & 1.35 & 1.33 & 1.37 & 0.03 \\
\hline 2003 & 1.34 & 1.35 & 1.33 & 1.37 & 0.03 \\
\hline 2004 & 1.36 & 1.36 & 1.35 & 1.38 & 0.02 \\
\hline 2005 & 1.34 & 1.35 & 1.33 & 1.35 & 0.01 \\
\hline 2006 & 1.33 & 1.34 & 1.32 & 1.34 & 0.01 \\
\hline 2007 & 1.37 & 1.38 & 1.36 & 1.37 & 0.00 \\
\hline \multicolumn{5}{|c|}{ Average deviation } & 0.01 \\
\hline
\end{tabular}

Source: Calculations based on N1 and N30suf.

B) Western Germany

Final TFR Confidence intervall Preliminary TFR Deviation preliminary TFR

\begin{tabular}{lccccc} 
Year & (N30suf) & UL & LL & (N10) & from final TFR \\
\hline 2001 & 1.38 & 1.39 & 1.37 & 1.38 & 0.00 \\
2002 & 1.37 & 1.38 & 1.36 & 1.38 & 0.01 \\
2003 & 1.36 & 1.37 & 1.35 & 1.36 & 0.00 \\
2004 & 1.37 & 1.38 & 1.36 & 1.38 & 0.00 \\
2005 & 1.35 & 1.36 & 1.34 & 1.35 & 0.00 \\
2006 & 1.34 & 1.35 & 1.33 & 1.34 & 0.00 \\
2007 & 1.37 & 1.38 & 1.36 & 1.37 & -0.01 \\
Average deviation & & & & 0.00
\end{tabular}

Source: Calculations based on N10 and N30suf.

\section{C) Eastern Germany}

Final TFR Confidence intervall Preliminary TFR Deviation preliminary TFR

\begin{tabular}{lccccc} 
Year & (N30suf) & UL & LL & (N10) & from final TFR \\
\hline 2001 & 1.23 & 1.25 & 1.21 & 1.20 & -0.03 \\
2002 & 1.24 & 1.26 & 1.22 & 1.21 & -0.02 \\
2003 & 1.26 & 1.28 & 1.24 & 1.24 & -0.02 \\
2004 & 1.31 & 1.33 & 1.29 & 1.29 & -0.02 \\
2005 & 1.30 & 1.32 & 1.28 & 1.27 & -0.02 \\
2006 & 1.30 & 1.32 & 1.28 & 1.28 & -0.02 \\
2007 & 1.37 & 1.39 & 1.35 & 1.34 & -0.03 \\
Average deviation & & & & -0.03
\end{tabular}

Source: Calculations based on N10 and N30suf. 


\section{Projection of the yearly TFR based on monthly rates}

We use our approach presented above to project the yearly TFR of the current year after the preliminary data for the months January to June have become available. We demonstrate the calculations using the years 2007 and 2008 as examples.

The projection procedure consists of three steps. Based on the retrospectively gathered preliminary data $N 1$, we first estimate cumulated monthly fertility rates for the years 2001 to 2006. Second, we calculate the proportion of the estimated cumulated TFR on the final yearly TFR based on the N30suf, which is published at a later date. Third, we use June as a cut-off point for the projection, because over the period 2001 to 2006, an average of $50 \%$ of the yearly TFR of the respective year was reached at the end of June.

Table 5 shows this procedure for the projection of the TFR for the year 2007, based on the previous five years 2001 to 2006, and the projection of the TFR for 2008 , based on the years 2002 to 2007 . We could test this method only for the years 2007 and 2008, since the method of data collection in N1 was changed in 2001. Therefore, data on the years before 2001 are not comparable with data after this year.

For the year 2007, the projected yearly TFR is 1.34 , which is an underestimation of 0.03 of the final TFR, and which, on the basis of N30suf, turned out to be 1.37. The

Tab. 5: Projection of the yearly German TFR, 2007 (based on years 2001 to 2006) and 2008 (based on years 2002 to 2007)

\begin{tabular}{lccc}
\hline $\begin{array}{l}\text { Year } \\
\text { Reference Period }\end{array}$ & $\begin{array}{c}\text { Preliminary } m \text { TFR } \\
\text { January-June }(N 1)\end{array}$ & $\begin{array}{c}\text { Final TFR } \\
\text { (N30suf) }\end{array}$ & $\begin{array}{c}\text { Proportion of } m \text { TFR January-June } \\
\text { from final TFR in \% }\end{array}$ \\
\hline 2001 & 0.676 & 1.346 & 50.3 \\
2002 & 0.678 & 1.339 & 50.7 \\
2003 & 0.674 & 1.338 & 50.4 \\
2004 & 0.674 & 1.357 & 49.7 \\
2005 & 0.667 & 1.338 & 49.9 \\
2006 & 0.659 & 1.329 & 49.5 \\
\hline 2007 & 0.668 & 1.368 & 48.8 \\
2008 & 0.685 & 1.376 & 49.6 \\
\hline Geom. Mean 2001-06 & & & $\mathbf{5 0 . 1}$ \\
Geom. Mean 2002-07 & & $\mathbf{1 . 3 3 5}$ & $\mathbf{4 9 . 8}$ \\
Projection TFR 2007 & & -0.034 & \\
Deviation from final TFR & & $\mathbf{1 . 3 7 5}$ & \\
Projection TFR 2008 & & -0.001 & \\
Deviation from final TFR & & & \\
\hline
\end{tabular}

Source: Calculations based on N1 and N30suf. 
reason for this underestimation is that from the middle of 2007 onwards, monthly birth rates are significantly higher than those in the previous year.

When we apply this simple technique to the 2008 data, our projection based on the births from January to June results in a yearly TFR of 1.38, which coincides with the final TFR at the end of 2008 (1.38).

\section{Discussion}

We have developed an approach for estimating the monthly TFR in the current year based on preliminary data that does not include the age of the mother at birth. Since this crucial information is only available for the previous year, we impute the age of the mother at birth in the current year by applying the age-specific birth rate to the data of the current year.

Timely information on the monthly TFR is of no help if the quality of the preliminary data is poor. This paper presents an overview of the various sources used for the calculation of the monthly fertility rates. Calculating these rates can be challenging because the different sources are available at different points in time, they refer to different regional units, and certain cases are excluded from certain sources. The data source that becomes available first is $N 1$. Here, the main problem is that the births are not correctly distributed to the month. N10, the data source that becomes available next, is supposed to provide more precise data, since it also includes information about whether the birth took place in eastern or in western Germany. However, we find that the estimations that are based on N10 are the least accurate, because the cases that are unclear are not included in these statistics. In addition, the case of Berlin is difficult to handle. In line with the practices of the statistical offices in Germany, we excluded Berlin from the estimations that are based on the N1O source. This leads to deviations of up to $10 \%$ from the final TFR in N30suf, which is, of course, most often an underestimation. Therefore, the results for eastern and western Germany based on N10 have to be interpreted with caution. If the goal is to have timely results for all of Germany, $N 1$ is the most accurate data source. If, on the other hand, the goal is to make a regional comparison, N10 can serve as a starting point. However, researchers using N10 should be aware that there will be a six-month delay before this data becomes available, and that a certain degree of underestimation of the fertility rates may be expected to occur.

Different opinions exist concerning the statistical treatment of the seasonal fluctuations in fertility. The Sobotka approach eliminates them which has the advantage that the level of fertility can be compared within a year. Changes in fertility patterns can thus be judged from one month to the other. Our approach keeps the seasonal fluctuations which has the advantage that users of the monitor are becoming aware of the large systematic fluctuations that occur over the course of a year. Another reason for keeping the seasonal fluctuations is the limited type of data that we are using. We have to approximate the age structure of the mothers, as well as the population at risk. We do not want to modify the data any further and thus decided to estimate the fertility rates that fit the aggregate number of births. Not adjusting for 
seasonality, however, has the disadvantage that the TFR of a specific month cannot be used as a predictor of the yearly TFR and that changes in fertility behaviour can only be evaluated in comparison to the same month of the previous year.

Our procedure systematically underestimates eastern German fertility. We trace this back to the assumption that the population of the previous year is an adequate estimation of the mid-term population of the current year. In fact, we know that this is not the case and that out-migration plays a large role in changing the underlying population structure in the eastern federal states. Future improvements of our procedure should thus explore to what extent out-migration can be incorporated into the estimates.

Despite the problems that arise from the data sources, we believe that our approach provides adequate monthly fertility rates. Nevertheless, we acknowledge that our method still has some shortcomings. For detailed research in the future, parity-specific data is necessary. Since this information is as yet missing from the German birth statistics, other sources have to be taken into account. A promising source could be the German perinatal statistics, which contains detailed information about the biological birth order (Kreyenfeld et al. 2010). Without implementation of parity-specific information, important demographic measures, such as the mean age at first birth or particular tempo standardizations, which are addressed in the Bongaarts-Feeney approach (2005), and parity-progression ratios as calculated in Sobotka et al. 2005, cannot be calculated.

Another shortcoming of our approach is that we assume the age distribution of births to be constant between the previous and the current year. This assumption is particularly problematic in eastern Germany, since the age distribution in that part of the country may be affected by high out-migration flows. A solution could be to implement a factor drawn from the previous years. Since migration behaviour is, however, the least predictable demographic force, an introduction of a migration adjustment seems problematic in itself. We are aware of the fact that the age-specific distribution of births varies permanently, with a relatively constant rate of change in several age groups. An easy solution could be the implementation of a sort of drift; i.e., to assume that the particular age-specific rates increase, while others decrease. In our opinion, a detailed time-series analysis would be necessary to attain that goal. One advantage of using such a procedure would be that it would allow us to model many different assumptions and scenarios regarding variations in the age distribution of births. A disadvantage of using time-series analysis is that we would need a sufficiently long time series, which would not be possible currently because adequate birth data have only been available since 2000 .

Our approach of projecting the yearly TFR of the current year based on preliminary monthly data up to June results in an estimate of high validity. The projection procedure works when there are no systematic differences between the birth rates in the first and second halves of the calendar year. If a substantial change occurs - which may, for example, be caused by social upheavals or considerable changes in family policies - early conclusions regarding yearly rates will prove incorrect, as was the case in the year 2007. By contrast, if we want to investigate the shortterm effects on birth behaviour of certain events, such as the introduction of family 
policies, we can use the monthly total fertility rates produced by our approach. For example, our approach was used to measure the impact on fertility rates of the new parental-leave benefit, which went into effect in Germany in January 2007. Since the new childcare benefit was not announced until in mid-2006, we expected that the effects of the new law would not become visible in the official birth statistics until the second half of 2007. In fact, we found significantly increased monthly fertility rates compared to the previous year from autumn 2007 onwards. This systematic change in fertility rates led to the underestimation in the projection of the final yearly TFR.

The number of births in Germany and the trends in fertility rates have been of great interest to the general public, and they feature prominently in the political discussion. Given the interest in this topic, it is surprising that official data on births are published with a considerable time lag, and that preliminary data lack important information for the calculation of fertility statistics. The result is that systematic changes in fertility, caused by new policies or societal changes, can only be detected with a considerable time lag. The monitoring procedure presented in this paper overcomes most of the data limitations of the preliminary data, and provides timely and adequate information on fertility trends in Germany. Our approach can detect systematic changes in fertility trends, such as in the second half of 2007, and it can project the final total fertility rate with a high degree of accuracy, after data have become available for the first six months. The monitoring procedure is implemented on the webpage www.rostockerzentrum.de/ and is updated monthly as soon as the latest data are published by Federal Statistical Office Germany (see Fig. A1 in the Appendix).

The authors are especially grateful to Johannes Klotz of Statistics Austria for advice on the project "Monitor of births", especially regarding the calculation of a TFR confidence interval. Comments and suggestions from the members of the Max Planck Institute for Demographic Research, Rostock, the Rostock Center for the Study of Demographic Change, and two anonymous reviewers are gratefully acknowledged. The publication on the webpage has been realized by Juliane Steinberg. We thank Miriam Hils for valuable language editing of the paper.

\section{References}

Bongaarts, John; Feeney, Griffith, 2005: The Quantum and Tempo of Life Cycle Events. Population Council, Working Paper 207. New York: Population Council

Calot, Gérard, 1981: L'observation de la fécondité à court et moyen terme. In: Population 36,1: 9-40

Calot, Gérard; Nadot, Robert, 1977: Combien y aura-t-il de naissances dans l'année? In: Population 32 (numero special): 185-229

Doblhammer, Gabriele; Rodgers, Joseph C.; Rau, Roland, 2000: Seasonality of birth in Nineteenth and Twentieth Century Austria. In: Social Biology 47,3: 201-217 
Flaskämper, Paul, 1962: Bevölkerungsstatistik. Mit einleitenden Ausführungen über den Gegenstand der Besonderen Sozialwissenschaftlichen Statistik überhaupt. Hamburg: Richard Meiner

Höhn, Charlotte, 1981: Die CALOT-Methode zur aktuellen Beurteilung von Geburtenniveau und -trend. In: Zeitschrift für Bevölkerungswissenschaft 7,2: 231-254

Kreyenfeld, Michaela; Scholz, Rembrandt; Peters, Frederik, Wlosnewski, Ines, 2010: Order-Specific Fertility Rates for Germany: Estimates from Perinatal Statistics for the Period 2001-2008. In: Comparative Population Studies 35,2: 207-224 [DOI: 10.4232/10. CPoS-2010-06en]

Lam, David A.; Miron, Jeffrey A., 1991: Seasonality of births in human populations. In: Social Biology 38: 51-78

Office for National Statistics, 2009: Review of the National Statistician on births and patterns of family building in England and Wales, 2008 [http://www.statistics.gov.uk/ downloads/theme_population/FM1-37/FM1-37.pdf]

Payton, Mark E.; Greenstone, Matthew; Schenker, Nathaniel, 2003: Overlapping confidence intervals or standard error intervals: What do they mean in terms of statistical significance? In: Journal of Insect Science 34,3: 34

Peters, Frederik; Milewski, Nadja; Doblhammer, Gabriele, 2009: The "Geburtenmonitor" - Estimating Births Rates in Germany on the Basis of Monthly Data. Discussion Paper No. 27 of the Rostock Center for the Study of Demographic Change. Rostock: RZ [http://www.rostockerzentrum.de/publikationen/rz_diskussionpapier_27.pdf]

Sobotka, Tomas et al., 2005: Monthly Estimates of the Quantum of Fertility: Towards a Fertility Monitoring System in Austria. In: Lutz, Wolfgang; Feichtinger, Gustav (Eds.): Vienna Yearbook of Population Research 2005. Vienna: Verlag der Österreichischen Akademie der Wissenschaften: 109-141 [DOI: 10.1553/populationyearbook2005s109]

A German translation of this authorised original article by Federal Institute for Population Research is available under the title "Monitor der Entwicklung der Geburtenhäufigkeit in Deutschland: Schätzung von monatlichen und jährlichen zusammengefassten Geburtenziffern auf der Grundlage vorläufiger monatlicher Daten", DOI 10.4232/10.CPOS-2010-07de or URN urn:nbn:de:bib-cpos-201007de0, at http://www.comparativepopulationstudies.de.

Dr. Nadja Milewski ( $₫)$, Prof. Dr. Gabriele Doblhammer, M. Sc. Frederik Peters. Rostock Center for the Study of Demographic Change, Konrad-Zuse-Str. 1, 18057 Rostock.

E-Mail: nadja.milewski@uni-rostock.de,doblhammer@rostockerzentrum.de,peters@ rostockerzentrum.de 


\section{Appendix}

\section{Example for the estimation of the preliminary mTFR in 2007}

Basic information given:

Number of births age 20 in 2006 (N30suf):

14,256

Total number of birth in 2006 (N30suf):

672,722

Number of births January 2007 (N1):

58,875

Population of age 19 in 2006:

475,857

Population of age 20 in 2006:

472,189

\section{Estimation for 2007:}

$1^{\text {st }}$ step: calculation of $r_{20,2007}$ according to equation (4)

$$
r_{20}(2007)=\frac{B_{20}^{N 30}(2006)}{\bar{P}_{20}^{f}(2006)}=\frac{14256}{472189}=\underline{\underline{0.030}}
$$

$\rightarrow \ln 2007$ the age-specific birth rate for age 20 is 0.030 .

$2^{\text {nd }}$ step: calculation of $B_{20}^{\text {const }}$ (2007) according to equation (5)

$$
\begin{aligned}
& B_{20}^{\text {const }}(2007)=r_{20}(2007) \cdot \bar{P}_{[19]}^{f}(2006) \\
& =0.030 \cdot 475857=14276
\end{aligned}
$$

$\rightarrow$ If the age-specific birth rate at age 20 had been the same as in 2006, 14,276 children would have been born in 2007.

$3^{\text {rd }}$ step: calculation of $B_{20}^{N 1}$ (January ,2007) according to equation (6):

$$
\begin{aligned}
& B_{20}^{N 1}(\text { January }, 2007)=\frac{B^{N 1}(\text { January }, 2007)}{\sum_{x=15}^{x=45} B_{x}^{\text {const }}(2007)} \cdot B_{20}^{\text {const }} \text { (2007) } \\
& =\frac{58857}{662407} \cdot 14276=\underline{\underline{1268}}
\end{aligned}
$$

$\rightarrow$ In January 2007, 1,268 births are estimated to have occurred at age 20. 
$4^{\text {th }}$ step: calculation of $m A S B R_{\text {January }}$ (2007) according to equation (7) and (9):

$$
\begin{aligned}
& m A S B R_{\text {January }}(2007)=\frac{B_{20}^{N 1}(\text { January })}{\bar{P}_{[19]}^{f}(2006)} \cdot \operatorname{caf}(\text { January }, 2007) \\
& =\frac{1268}{475857} \cdot \frac{365}{31}=\underline{\underline{0.0314}}
\end{aligned}
$$

$\rightarrow$ In January 2007 for every woman at age 20, 0.0314 children are estimated. Summed up over ages 15 to 45, the monthly total fertility rate is computed, which represents the number of children a woman would have had if the conditions in January had been constant throughout the whole year 2007.

\section{Online-Publication of the "Monitor of births" at the Rostock Centre for Demographic Change}

The "Monitor of births" is updated monthly for total Germany, the regional levels of Germany, eastern Germany and western Germany. In addition, a virtual press kit is published as soon as the new estimation of the yearly TFR is calculated, see www. rostockerzentrum.de/. Figure A1 is an example from the website, which is published in German. The solid line represents final data based on N30suf. Preliminary data (N1 and N10) are presented as dashed line. Below the line chart, bars indicate the respective differences between a given month and the same month of the previous year. Here, the arrows show significant differences at a confidence level of $95 \%$, which is performed only for final data. Lastly, the two boxes in the upper section of the chart contain the most recent final and preliminary monthly TFR. 
Fig. A1: Monthly TFR for Germany, July 2004 to June 2009, as published on the website (in German only)

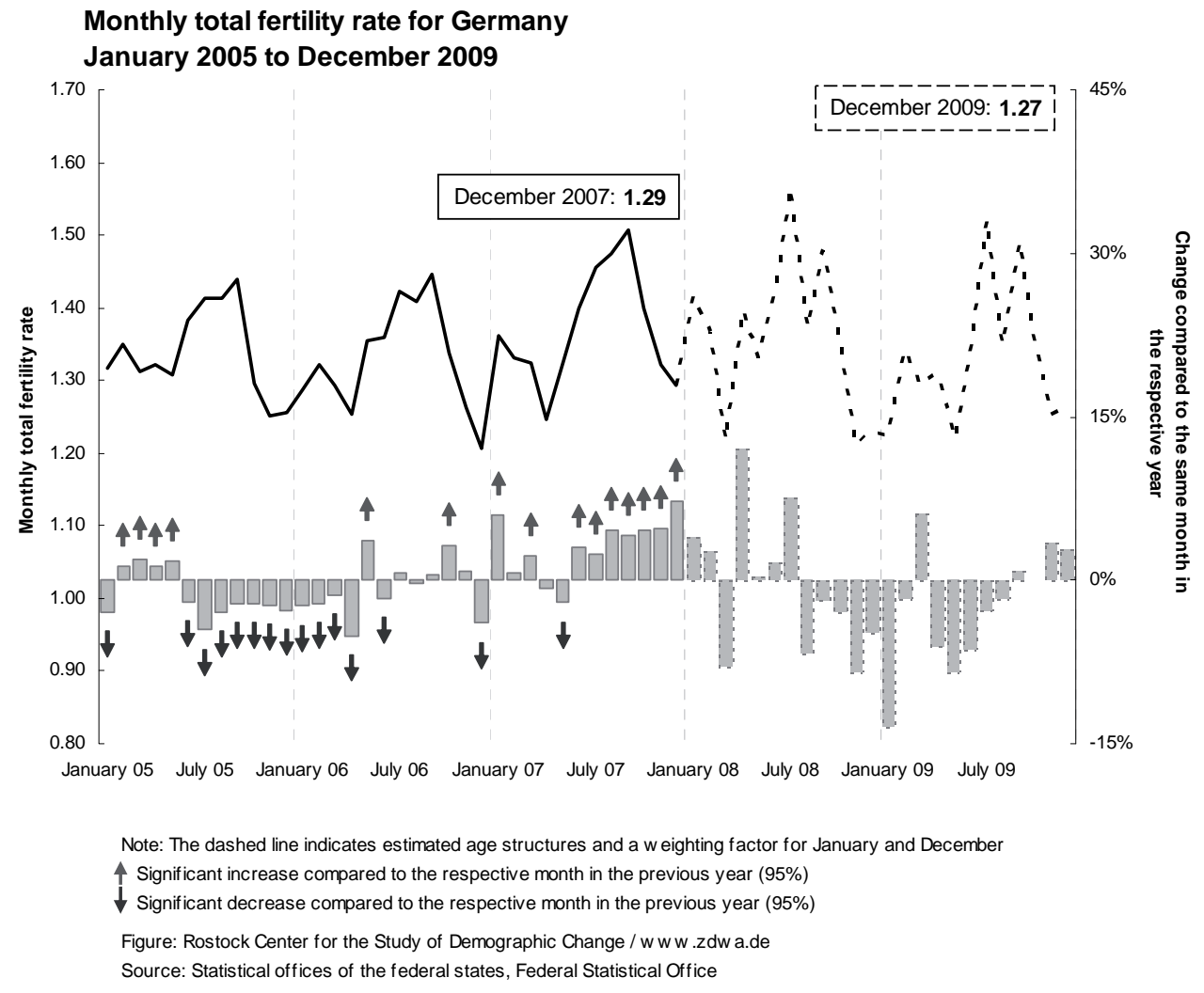


Tab. A1a: Estimations of $m T F R$ in 2001 to 2006, Germany - confidence intervals and absolute errors

\begin{tabular}{|c|c|c|c|c|c|}
\hline \multirow{2}{*}{$\begin{array}{l}2001 \\
\text { Month }\end{array}$} & \multirow{2}{*}{$\begin{array}{l}\text { Final } m T F R \\
\text { (N30suf) }\end{array}$} & \multicolumn{2}{|c|}{ Confidence intervall } & \multirow{2}{*}{$\begin{array}{c}\text { Preliminary } m T F R \\
\text { (N1) }\end{array}$} & \multirow{2}{*}{$\begin{array}{l}\text { Deviation preliminary } m T F R \\
\text { from final } m T F R\end{array}$} \\
\hline & & UL & LL & & \\
\hline January & 1.38 & 1.39 & 1.37 & 1.41 & 0.03 \\
\hline February & 1.33 & 1.33 & 1.32 & 1.35 & 0.02 \\
\hline March & 1.32 & 1.32 & 1.31 & 1.33 & 0.02 \\
\hline April & 1.31 & 1.32 & 1.30 & 1.27 & -0.04 \\
\hline May & 1.36 & 1.37 & 1.35 & 1.43 & 0.07 \\
\hline June & 1.37 & 1.38 & 1.36 & 1.33 & -0.04 \\
\hline July & 1.43 & 1.44 & 1.42 & 1.45 & 0.02 \\
\hline August & 1.42 & 1.42 & 1.41 & 1.46 & 0.05 \\
\hline September & 1.41 & 1.41 & 1.40 & 1.33 & -0.07 \\
\hline October & 1.32 & 1.33 & 1.31 & 1.44 & 0.12 \\
\hline November & 1.28 & 1.28 & 1.27 & 1.31 & 0.04 \\
\hline December & 1.24 & 1.25 & 1.23 & 1.09 & -0.15 \\
\hline 2002 & Final $m T F R$ & \multicolumn{2}{|c|}{ Confidence intervall } & Preliminary $m T F R$ & Deviation preliminary $m T F R$ \\
\hline Month & (N30suf) & UL & LL & (N1) & from final $m T F R$ \\
\hline January & 1.34 & 1.34 & 1.33 & 1.49 & 0.15 \\
\hline February & 1.35 & 1.36 & 1.35 & 1.38 & 0.03 \\
\hline March & 1.33 & 1.34 & 1.32 & 1.26 & -0.07 \\
\hline April & 1.31 & 1.32 & 1.30 & 1.42 & 0.11 \\
\hline May & 1.29 & 1.30 & 1.28 & 1.30 & 0.01 \\
\hline June & 1.34 & 1.35 & 1.33 & 1.30 & -0.04 \\
\hline July & 1.43 & 1.43 & 1.42 & 1.51 & 0.08 \\
\hline August & 1.39 & 1.40 & 1.39 & 1.40 & 0.01 \\
\hline September & 1.44 & 1.45 & 1.43 & 1.44 & 0.00 \\
\hline October & 1.34 & 1.35 & 1.33 & 1.44 & 0.10 \\
\hline November & 1.25 & 1.26 & 1.25 & 1.26 & 0.01 \\
\hline December & 1.26 & 1.27 & 1.25 & 1.19 & -0.06 \\
\hline 2003 & Final $m T F R$ & \multicolumn{2}{|c|}{ Confidence intervall } & Preliminary $m T F R$ & Deviation preliminary $m T F R$ \\
\hline Month & (N30suf) & UL & $\mathrm{LL}$ & (N1) & from final $m T F R$ \\
\hline January & 1.32 & 1.32 & 1.31 & 1.45 & 0.13 \\
\hline February & 1.32 & 1.33 & 1.31 & 1.35 & 0.03 \\
\hline March & 1.28 & 1.29 & 1.27 & 1.28 & 0.01 \\
\hline April & 1.31 & 1.32 & 1.30 & 1.33 & 0.02 \\
\hline May & 1.32 & 1.33 & 1.31 & 1.28 & -0.04 \\
\hline June & 1.36 & 1.37 & 1.36 & 1.39 & 0.02 \\
\hline July & 1.47 & 1.48 & 1.46 & 1.54 & 0.07 \\
\hline August & 1.40 & 1.41 & 1.39 & 1.35 & -0.04 \\
\hline September & 1.47 & 1.47 & 1.46 & 1.51 & 0.05 \\
\hline October & 1.32 & 1.32 & 1.31 & 1.41 & 0.10 \\
\hline November & 1.24 & 1.25 & 1.23 & 1.22 & -0.03 \\
\hline December & 1.25 & 1.25 & 1.24 & 1.27 & 0.02 \\
\hline
\end{tabular}




\begin{tabular}{|c|c|c|c|c|c|}
\hline \multirow{2}{*}{$\begin{array}{l}2004 \\
\text { Month }\end{array}$} & \multirow{2}{*}{$\begin{array}{l}\text { Final } m \text { TFR } \\
\text { (N30suf) }\end{array}$} & \multicolumn{2}{|c|}{ Confidence intervall } & \multirow{2}{*}{$\begin{array}{l}\text { Preliminary } m T F R \\
\text { (N1) }\end{array}$} & \multirow{2}{*}{$\begin{array}{c}\text { Deviation preliminary } m T F R \\
\text { from final } m T F R\end{array}$} \\
\hline & & UL & LL & & \\
\hline January & 1.36 & 1.36 & 1.35 & 1.38 & 0.02 \\
\hline February & 1.33 & 1.34 & 1.32 & 1.34 & 0.00 \\
\hline March & 1.29 & 1.29 & 1.28 & 1.38 & 0.10 \\
\hline April & 1.31 & 1.31 & 1.30 & 1.33 & 0.03 \\
\hline May & 1.28 & 1.29 & 1.28 & 1.18 & -0.10 \\
\hline June & 1.41 & 1.42 & 1.40 & 1.48 & 0.07 \\
\hline July & 1.48 & 1.49 & 1.47 & 1.46 & -0.02 \\
\hline August & 1.46 & 1.46 & 1.45 & 1.51 & 0.05 \\
\hline September & 1.47 & 1.48 & 1.46 & 1.51 & 0.04 \\
\hline October & 1.32 & 1.33 & 1.32 & 1.30 & -0.02 \\
\hline November & 1.28 & 1.29 & 1.27 & 1.36 & 0.08 \\
\hline December & 1.29 & 1.30 & 1.28 & 1.32 & 0.03 \\
\hline 2005 & Final $m T F R$ & \multicolumn{2}{|c|}{ Confidence intervall } & Preliminary $m T F R$ & Deviation preliminary $m T F R$ \\
\hline Month & (N30suf) & UL & LL & (N1) & from final $m T F R$ \\
\hline January & 1.32 & 1.32 & 1.31 & 1.27 & -0.05 \\
\hline February & 1.35 & 1.36 & 1.34 & 1.35 & 0.00 \\
\hline March & 1.31 & 1.32 & 1.30 & 1.31 & -0.01 \\
\hline April & 1.32 & 1.33 & 1.31 & 1.33 & 0.01 \\
\hline May & 1.31 & 1.31 & 1.30 & 1.32 & 0.02 \\
\hline June & 1.38 & 1.39 & 1.37 & 1.43 & 0.05 \\
\hline July & 1.41 & 1.42 & 1.40 & 1.34 & -0.07 \\
\hline August & 1.41 & 1.42 & 1.41 & 1.49 & 0.08 \\
\hline September & 1.44 & 1.45 & 1.43 & 1.43 & -0.01 \\
\hline October & 1.30 & 1.30 & 1.29 & 1.30 & 0.00 \\
\hline November & 1.25 & 1.26 & 1.24 & 1.33 & 0.07 \\
\hline December & 1.26 & 1.26 & 1.25 & 1.26 & 0.01 \\
\hline 2006 & Final $m T F R$ & \multicolumn{2}{|c|}{ Confidence intervall } & Preliminary $m T F R$ & Deviation preliminary $m T F R$ \\
\hline Month & (N30suf) & UL & LL & $(N 1)$ & from final $m T F R$ \\
\hline January & 1.29 & 1.29 & 1.28 & 1.30 & 0.01 \\
\hline February & 1.32 & 1.33 & 1.31 & 1.32 & 0.00 \\
\hline March & 1.29 & 1.30 & 1.29 & 1.33 & 0.04 \\
\hline April & 1.25 & 1.26 & 1.25 & 1.16 & -0.09 \\
\hline May & 1.35 & 1.36 & 1.35 & 1.41 & 0.05 \\
\hline June & 1.36 & 1.37 & 1.35 & 1.38 & 0.03 \\
\hline July & 1.42 & 1.43 & 1.41 & 1.36 & -0.06 \\
\hline August & 1.41 & 1.42 & 1.40 & 1.49 & 0.08 \\
\hline September & 1.45 & 1.46 & 1.44 & 1.41 & -0.04 \\
\hline October & 1.34 & 1.35 & 1.33 & 1.38 & 0.04 \\
\hline November & 1.26 & 1.27 & 1.25 & 1.34 & 0.08 \\
\hline December & 1.21 & 1.21 & 1.20 & 1.16 & -0.05 \\
\hline
\end{tabular}

Source: Calculations based on N1 and N30suf. 
Tab. A1b: Estimations of $m T F R$ in 2001 to 2006, western Germany - confidence intervals and absolute errors

\begin{tabular}{|c|c|c|c|c|c|}
\hline \multirow{2}{*}{$\begin{array}{l}2001 \\
\text { Month }\end{array}$} & \multirow{2}{*}{$\begin{array}{l}\text { Final } m \text { TFR } \\
\text { (N30suf) }\end{array}$} & \multicolumn{2}{|c|}{ Confidence intervall } & \multirow{2}{*}{$\begin{array}{l}\text { Preliminary } m T F R \\
\text { (N10) }\end{array}$} & \multirow{2}{*}{$\begin{array}{l}\text { Deviation preliminary } m T F R \\
\text { from final } m T F R\end{array}$} \\
\hline & & UL & LL & & \\
\hline January & 1.42 & 1.43 & 1.41 & 1.39 & -0.03 \\
\hline February & 1.36 & 1.37 & 1.35 & 1.34 & -0.02 \\
\hline March & 1.35 & 1.35 & 1.34 & 1.35 & 0.00 \\
\hline April & 1.34 & 1.35 & 1.33 & 1.30 & -0.04 \\
\hline May & 1.40 & 1.41 & 1.39 & 1.47 & 0.07 \\
\hline June & 1.41 & 1.41 & 1.40 & 1.37 & -0.04 \\
\hline July & 1.46 & 1.47 & 1.45 & 1.48 & 0.01 \\
\hline August & 1.45 & 1.46 & 1.44 & 1.49 & 0.04 \\
\hline September & 1.44 & 1.45 & 1.43 & 1.37 & -0.07 \\
\hline October & 1.35 & 1.36 & 1.34 & 1.46 & 0.11 \\
\hline November & 1.31 & 1.32 & 1.30 & 1.33 & 0.02 \\
\hline December & 1.27 & 1.28 & 1.26 & 1.21 & -0.06 \\
\hline 2002 & Final $m T F R$ & \multicolumn{2}{|c|}{ Confidence intervall } & Preliminary $m T F R$ & Deviation preliminary $m T F R$ \\
\hline Month & (N30suf) & UL & $\mathrm{LL}$ & $(N 10)$ & from final $m T F R$ \\
\hline January & 1.36 & 1.37 & 1.36 & 1.35 & -0.02 \\
\hline February & 1.39 & 1.40 & 1.38 & 1.38 & -0.01 \\
\hline March & 1.37 & 1.37 & 1.36 & 1.29 & -0.08 \\
\hline April & 1.34 & 1.35 & 1.34 & 1.44 & 0.10 \\
\hline May & 1.32 & 1.32 & 1.31 & 1.32 & 0.00 \\
\hline June & 1.37 & 1.38 & 1.36 & 1.33 & -0.04 \\
\hline July & 1.45 & 1.46 & 1.44 & 1.53 & 0.08 \\
\hline August & 1.42 & 1.43 & 1.41 & 1.41 & -0.01 \\
\hline September & 1.47 & 1.48 & 1.46 & 1.45 & -0.02 \\
\hline October & 1.37 & 1.38 & 1.36 & 1.49 & 0.12 \\
\hline November & 1.28 & 1.29 & 1.27 & 1.28 & 0.01 \\
\hline December & 1.29 & 1.30 & 1.28 & 1.25 & -0.04 \\
\hline 2003 & Final $m T F R$ & \multicolumn{2}{|c|}{ Confidence intervall } & Preliminary $m T F R$ & Deviation preliminary $m T F R$ \\
\hline Month & (N30suf) & UL & LL & $(N 10)$ & from final $m T F R$ \\
\hline January & 1.35 & 1.36 & 1.34 & 1.31 & -0.04 \\
\hline February & 1.35 & 1.36 & 1.34 & 1.35 & 0.00 \\
\hline March & 1.30 & 1.31 & 1.29 & 1.28 & -0.02 \\
\hline April & 1.34 & 1.35 & 1.33 & 1.36 & 0.02 \\
\hline May & 1.35 & 1.36 & 1.34 & 1.31 & -0.04 \\
\hline June & 1.39 & 1.40 & 1.38 & 1.40 & 0.01 \\
\hline July & 1.49 & 1.50 & 1.48 & 1.57 & 0.08 \\
\hline August & 1.42 & 1.43 & 1.41 & 1.38 & -0.04 \\
\hline September & 1.48 & 1.49 & 1.47 & 1.52 & 0.04 \\
\hline October & 1.34 & 1.34 & 1.33 & 1.43 & 0.10 \\
\hline November & 1.27 & 1.27 & 1.26 & 1.22 & -0.04 \\
\hline December & 1.27 & 1.28 & 1.26 & 1.25 & -0.01 \\
\hline
\end{tabular}




\begin{tabular}{|c|c|c|c|c|c|}
\hline \multirow{2}{*}{$\begin{array}{l}2004 \\
\text { Month }\end{array}$} & \multirow{2}{*}{$\begin{array}{l}\text { Final mTFR } \\
\text { (N30suf) }\end{array}$} & \multicolumn{2}{|c|}{ Confidence intervall } & \multirow{2}{*}{$\begin{array}{c}\text { Preliminary } m T F R \\
\text { (N10) }\end{array}$} & \multirow{2}{*}{$\begin{array}{c}\text { Deviation preliminary } m T F R \\
\text { from final } m T F R\end{array}$} \\
\hline & & UL & LL & & \\
\hline January & 1.38 & 1.39 & 1.37 & 1.32 & -0.06 \\
\hline February & 1.35 & 1.36 & 1.34 & 1.30 & -0.05 \\
\hline March & 1.30 & 1.31 & 1.29 & 1.40 & 0.10 \\
\hline April & 1.32 & 1.32 & 1.31 & 1.33 & 0.01 \\
\hline May & 1.30 & 1.31 & 1.30 & 1.20 & -0.11 \\
\hline June & 1.43 & 1.43 & 1.42 & 1.51 & 0.09 \\
\hline July & 1.49 & 1.50 & 1.48 & 1.47 & -0.02 \\
\hline August & 1.47 & 1.48 & 1.46 & 1.52 & 0.04 \\
\hline September & 1.49 & 1.49 & 1.48 & 1.53 & 0.05 \\
\hline October & 1.34 & 1.35 & 1.33 & 1.32 & -0.03 \\
\hline November & 1.30 & 1.31 & 1.29 & 1.36 & 0.06 \\
\hline December & 1.31 & 1.32 & 1.30 & 1.25 & -0.05 \\
\hline 2005 & Final $m T F R$ & \multicolumn{2}{|c|}{ Confidence intervall } & Preliminary $m T F R$ & Deviation preliminary $m T F R$ \\
\hline Month & (N30suf) & UL & LL & $(N 10)$ & from final $m T F R$ \\
\hline January & 1.34 & 1.35 & 1.33 & 1.25 & -0.08 \\
\hline February & 1.37 & 1.38 & 1.36 & 1.33 & -0.03 \\
\hline March & 1.33 & 1.34 & 1.32 & 1.35 & 0.02 \\
\hline April & 1.34 & 1.35 & 1.33 & 1.35 & 0.01 \\
\hline May & 1.32 & 1.33 & 1.32 & 1.33 & 0.01 \\
\hline June & 1.40 & 1.40 & 1.39 & 1.44 & 0.04 \\
\hline July & 1.42 & 1.43 & 1.41 & 1.34 & -0.08 \\
\hline August & 1.43 & 1.43 & 1.42 & 1.50 & 0.08 \\
\hline September & 1.45 & 1.46 & 1.45 & 1.46 & 0.01 \\
\hline October & 1.31 & 1.32 & 1.30 & 1.32 & 0.01 \\
\hline November & 1.26 & 1.27 & 1.25 & 1.32 & 0.06 \\
\hline December & 1.27 & 1.28 & 1.26 & 1.22 & -0.06 \\
\hline 2006 & Final $m T F R$ & \multicolumn{2}{|c|}{ Confidence intervall } & Preliminary $m T F R$ & Deviation preliminary $m T F R$ \\
\hline Month & (N30suf) & UL & LL & $(N 10)$ & from final $m T F R$ \\
\hline January & 1.30 & 1.31 & 1.29 & 1.23 & -0.07 \\
\hline February & 1.34 & 1.35 & 1.33 & 1.30 & -0.04 \\
\hline March & 1.31 & 1.31 & 1.30 & 1.37 & 0.06 \\
\hline April & 1.26 & 1.27 & 1.25 & 1.18 & -0.08 \\
\hline May & 1.36 & 1.37 & 1.35 & 1.41 & 0.05 \\
\hline June & 1.37 & 1.38 & 1.36 & 1.39 & 0.02 \\
\hline July & 1.43 & 1.43 & 1.42 & 1.37 & -0.05 \\
\hline August & 1.41 & 1.42 & 1.40 & 1.50 & 0.08 \\
\hline September & 1.46 & 1.46 & 1.45 & 1.40 & -0.06 \\
\hline October & 1.35 & 1.36 & 1.34 & 1.40 & 0.05 \\
\hline November & 1.27 & 1.28 & 1.26 & 1.33 & 0.06 \\
\hline December & 1.21 & 1.22 & 1.21 & 1.16 & -0.05 \\
\hline
\end{tabular}

Note: January weighted by 0.75 , December weighted by 1.25 .

Source: Calculations based on N10 and N30suf. 
Tab. A1c: Estimations of $m T F R$ in 2001 to 2006, eastern Germany - confidence intervals and absolute errors

\begin{tabular}{|c|c|c|c|c|c|}
\hline \multirow{2}{*}{$\begin{array}{l}2001 \\
\text { Month }\end{array}$} & \multirow{2}{*}{$\begin{array}{l}\text { Final } m \text { TFR } \\
\text { (N30suf) }\end{array}$} & \multicolumn{2}{|c|}{ Confidence intervall } & \multirow{2}{*}{$\begin{array}{l}\text { Preliminary } m T F R \\
\text { (N10) }\end{array}$} & \multirow{2}{*}{$\begin{array}{l}\text { Deviation preliminary } m T F R \\
\text { from final } m T F R\end{array}$} \\
\hline & & UL & LL & & \\
\hline January & 1.24 & 1.26 & 1.22 & 1.27 & 0.03 \\
\hline February & 1.21 & 1.23 & 1.19 & 1.17 & -0.04 \\
\hline March & 1.21 & 1.23 & 1.19 & 1.16 & -0.05 \\
\hline April & 1.20 & 1.22 & 1.18 & 1.13 & -0.07 \\
\hline May & 1.25 & 1.27 & 1.23 & 1.27 & 0.02 \\
\hline June & 1.24 & 1.26 & 1.22 & 1.16 & -0.07 \\
\hline July & 1.35 & 1.37 & 1.33 & 1.33 & -0.02 \\
\hline August & 1.30 & 1.32 & 1.28 & 1.27 & -0.04 \\
\hline September & 1.29 & 1.31 & 1.27 & 1.20 & -0.09 \\
\hline October & 1.20 & 1.22 & 1.18 & 1.22 & 0.02 \\
\hline November & 1.16 & 1.18 & 1.14 & 1.17 & 0.00 \\
\hline December & 1.11 & 1.13 & 1.10 & 1.03 & -0.08 \\
\hline 2002 & Final $m T F R$ & \multicolumn{2}{|c|}{ Confidence intervall } & Preliminary $m T F R$ & Deviation preliminary $m T F R$ \\
\hline Month & (N30suf) & UL & $\mathrm{LL}$ & $(N 10)$ & from final $m T F R$ \\
\hline January & 1.22 & 1.24 & 1.20 & 1.23 & 0.02 \\
\hline February & 1.22 & 1.24 & 1.20 & 1.20 & -0.02 \\
\hline March & 1.21 & 1.23 & 1.19 & 1.11 & -0.10 \\
\hline April & 1.21 & 1.22 & 1.19 & 1.26 & 0.06 \\
\hline May & 1.20 & 1.22 & 1.19 & 1.18 & -0.03 \\
\hline June & 1.24 & 1.25 & 1.22 & 1.14 & -0.10 \\
\hline July & 1.35 & 1.37 & 1.33 & 1.37 & 0.02 \\
\hline August & 1.31 & 1.33 & 1.29 & 1.26 & -0.05 \\
\hline September & 1.34 & 1.36 & 1.32 & 1.32 & -0.02 \\
\hline October & 1.24 & 1.25 & 1.22 & 1.25 & 0.02 \\
\hline November & 1.17 & 1.18 & 1.15 & 1.16 & 0.00 \\
\hline December & 1.15 & 1.16 & 1.13 & 1.08 & -0.06 \\
\hline 2003 & Final $m T F R$ & \multicolumn{2}{|c|}{ Confidence intervall } & Preliminary $m T F R$ & Deviation preliminary $m T F R$ \\
\hline Month & (N30suf) & UL & $\mathrm{LL}$ & $(N 10)$ & from final $m T F R$ \\
\hline January & 1.18 & 1.20 & 1.16 & 1.20 & 0.01 \\
\hline February & 1.20 & 1.22 & 1.18 & 1.18 & -0.02 \\
\hline March & 1.19 & 1.21 & 1.18 & 1.15 & -0.04 \\
\hline April & 1.23 & 1.24 & 1.21 & 1.22 & 0.00 \\
\hline May & 1.23 & 1.25 & 1.22 & 1.15 & -0.09 \\
\hline June & 1.30 & 1.32 & 1.28 & 1.28 & -0.01 \\
\hline July & 1.42 & 1.44 & 1.40 & 1.46 & 0.03 \\
\hline August & 1.35 & 1.37 & 1.33 & 1.25 & -0.11 \\
\hline September & 1.44 & 1.46 & 1.42 & 1.48 & 0.03 \\
\hline October & 1.26 & 1.28 & 1.24 & 1.26 & 0.00 \\
\hline November & 1.16 & 1.18 & 1.14 & 1.13 & -0.03 \\
\hline December & 1.18 & 1.20 & 1.16 & 1.14 & -0.04 \\
\hline
\end{tabular}




\begin{tabular}{|c|c|c|c|c|c|}
\hline \multirow{2}{*}{$\begin{array}{l}2004 \\
\text { Month }\end{array}$} & \multirow{2}{*}{$\begin{array}{l}\text { Final } m T F R \\
\text { (N30suf) }\end{array}$} & \multicolumn{2}{|c|}{ Confidence intervall } & \multirow{2}{*}{$\begin{array}{c}\text { Preliminary } m T F R \\
\text { (N10) }\end{array}$} & \multirow{2}{*}{$\begin{array}{l}\text { Deviation preliminary } m T F R \\
\text { from final } m T F R\end{array}$} \\
\hline & & UL & LL & & \\
\hline January & 1.29 & 1.31 & 1.27 & 1.24 & -0.05 \\
\hline February & 1.27 & 1.28 & 1.25 & 1.21 & -0.05 \\
\hline March & 1.25 & 1.27 & 1.23 & 1.30 & 0.06 \\
\hline April & 1.28 & 1.30 & 1.26 & 1.24 & -0.03 \\
\hline May & 1.22 & 1.24 & 1.21 & 1.11 & -0.12 \\
\hline June & 1.37 & 1.39 & 1.35 & 1.44 & 0.07 \\
\hline July & 1.47 & 1.50 & 1.45 & 1.41 & -0.07 \\
\hline August & 1.43 & 1.45 & 1.41 & 1.46 & 0.03 \\
\hline September & 1.43 & 1.45 & 1.41 & 1.42 & -0.01 \\
\hline October & 1.26 & 1.28 & 1.24 & 1.20 & -0.06 \\
\hline November & 1.21 & 1.23 & 1.19 & 1.27 & 0.06 \\
\hline December & 1.24 & 1.26 & 1.22 & 1.16 & -0.08 \\
\hline 2005 & Final $m T F R$ & \multicolumn{2}{|c|}{ Confidence intervall } & Preliminary $m T F R$ & Deviation preliminary $m T F R$ \\
\hline Month & (N30suf) & UL & LL & $(N 10)$ & from final $m T F R$ \\
\hline January & 1.24 & 1.26 & 1.22 & 1.18 & -0.07 \\
\hline February & 1.30 & 1.32 & 1.28 & 1.28 & -0.02 \\
\hline March & 1.24 & 1.26 & 1.22 & 1.25 & 0.00 \\
\hline April & 1.28 & 1.29 & 1.26 & 1.23 & -0.04 \\
\hline May & 1.25 & 1.27 & 1.23 & 1.26 & 0.01 \\
\hline June & 1.36 & 1.38 & 1.34 & 1.33 & -0.03 \\
\hline July & 1.40 & 1.42 & 1.38 & 1.30 & -0.10 \\
\hline August & 1.38 & 1.41 & 1.36 & 1.43 & 0.05 \\
\hline September & 1.40 & 1.42 & 1.38 & 1.39 & -0.01 \\
\hline October & 1.25 & 1.27 & 1.23 & 1.15 & -0.09 \\
\hline November & 1.24 & 1.26 & 1.22 & 1.33 & 0.08 \\
\hline December & 1.20 & 1.22 & 1.18 & 1.15 & -0.05 \\
\hline 2006 & Final $m T F R$ & \multicolumn{2}{|c|}{ Confidence intervall } & Preliminary $m T F R$ & Deviation preliminary $m T F R$ \\
\hline Month & (N30suf) & UL & LL & (N10) & from final $m T F R$ \\
\hline January & 1.21 & 1.23 & 1.19 & 1.19 & -0.02 \\
\hline February & 1.26 & 1.28 & 1.24 & 1.23 & -0.02 \\
\hline March & 1.26 & 1.28 & 1.24 & 1.24 & -0.02 \\
\hline April & 1.23 & 1.25 & 1.21 & 1.13 & -0.10 \\
\hline May & 1.33 & 1.35 & 1.31 & 1.35 & 0.02 \\
\hline June & 1.34 & 1.36 & 1.32 & 1.33 & 0.00 \\
\hline July & 1.43 & 1.45 & 1.41 & 1.35 & -0.08 \\
\hline August & 1.42 & 1.44 & 1.40 & 1.44 & 0.02 \\
\hline September & 1.44 & 1.46 & 1.42 & 1.38 & -0.06 \\
\hline October & 1.30 & 1.32 & 1.28 & 1.24 & -0.06 \\
\hline November & 1.23 & 1.25 & 1.21 & 1.35 & 0.12 \\
\hline December & 1.17 & 1.19 & 1.15 & 1.11 & -0.06 \\
\hline
\end{tabular}

Note: January weighted by 0.8 , December weighted by 1.2 .

Source: Calculations based on N10 and N30suf. 


\section{Comparative Population Studies - Zeitschrift für Bevölkerungswissenschaft}

wWw.comparativepopulationstudies.de

ISSN: 1869-8980 (Print) - 1869-8999 (Internet)

Published by / Herausgegeben von

Prof. Dr. Norbert F. Schneider

Layout and print: Federal Institute for Population Research, Wiesbaden

(Germany)

\section{Managing Editor / Redaktion}

Frank Swiaczny

Copy Editor / Schlußredaktion

Dr. Evelyn Grünheid

\section{Scientific Advisory Board / \\ Wissenschaftlicher Beirat}

Jürgen Dorbritz (Wiesbaden)

Paul Gans (Mannheim)

Johannes Huinink (Bremen)

Dirk J. van de Kaa (Den Haag)

Marc Luy (Wien)

Notburga Ott (Bochum)

Peter Preisendörfer (Mainz)

\section{Board of Reviewers / Gutachterbeirat}

Martin Abraham (Erlangen)

Laura Bernardi (Lausanne)

Hansjörg Bucher (Bonn)

Claudia Diehl (Göttingen)

Andreas Diekmann (Zürich)

Gabriele Doblhammer-Reiter (Rostock)

Henriette Engelhardt-Wölfler (Bamberg)

E.-Jürgen Flöthmann (Bielefeld)

Alexia Fürnkranz-Prskawetz (Wien)

Beat Fux (Zürich)

Joshua Goldstein (Rostock)

Karsten Hank (Mannheim)

Sonja Haug (Regensburg)

Franz-Josef Kemper (Berlin)

Hans-Peter Kohler (Philadelphia)

Michaela Kreyenfeld (Rostock)

Aart C. Liefbroer (Den Haag)

Kurt Lüscher (Konstanz)

Dimiter Philipov (Wien)

Tomáš Sobotka (Wien)

Heike Trappe (Rostock) 